210 Ueber den Ursprung des Schildlacks. - Untersuchung der Presshefe.

das Finzelberg'sche 10,9-14,7\% des in Arbeit genommenen Eiweisses. Bei einem andern Versuche mit vollständiger Lösung des Eiweisses belief sich die Menge des Syntonin-Niederschlages für das Witte'sche auf $17,0 \%$, die des Finzelberg'schen auf $10-13,2 \%$.

Aus diesen Resultaten erhellt zur Genüge, dass sowohl vermöge seiner physicalischen Beschaffenheit als insbesondere seiner verdauenden und peptonisirenden Wirkung das Finzelberg'sche Pepsin dem Witte'schen sogar etwas überlegen ist, mindestens aber sich mit demselben auf die gleiche Stufe stellen kann.

Bemerkt sei noch, dass die 4 mir zur Verfügung stehenden, von verschiedenen Qellen stammenden Finzelberg'schen Pepsinproben ihrer Wirkung und ihrem Aussehen nach sich vollständig identisch erwiesen.

\title{
B. Monatsberieht.
}

Ueber den Ursprung des Schildlacks. - Man nahm bisher an, dass dieser Lack ein Pflanzenexsudat sei, hervorgerufen durch den Rüsselstich des Lack-Insectes Coccus Lacca. Stillmann erklärt dagegen den Lack für ein Product des Insectes und nicht des Baumes, und unterstützt seine Ansicht mit folgenden Argumenten: Der Gummilack ist kein einfaches vegetabilisches Harz, sondern besteht aus in Alkohol löslichen Harzen sowohl, wie auch aus Wachs und Gluten oder glutenartigen Substanzen; eine solche Complication kann nur thierischen Ursprungs sein. Das Harz besitzt ferner im Allgemeinen gleiche Zusammensetzung und Eigenschaften, unabhängig von der Pflanzenart, von welcher es herrïhrt. Es konnten endlich bei sorgfältigen Untersuchungen von Rinde und Holz keine Verletzungen gefunden werden, die für ein Einbobren des Insectes und dadurch verursachtes Exsudat sprächen. (Amerikan. Apoth.-Zeitg. No. 18.)

G. $\boldsymbol{H}$.

Untersuchung der Presshefe. - Als Verfälschungsmittel der Presshefe dient neben mineralischen Substanzen, wie Gyps, vorzugsweise die Stärke. Der einfache Nachweis der Stärke durch das Mikroskop genügt jedoch nicht, um eine Verf̈̈lschung zu constatiren, weil Stärke auch aus technischen Gründen der Hefe zugesetzt wird. Da dieselbe ausserdem die Wirkung der Hefe durchaus nicht beeinträchtigt, so kann von einer Fölschung nur dann 
die Rede sein, wenn ibre Merge nicht auf Kosten des Wassergehaltes der Presshefe, der 60-80\% beträgt, sondern auf Kosten der reinen Hefe vermehrt ist. Neben der Stärke muss demnach auch jedesmal die Menge des Wassers bestimmt werden. Man könnte die Stärke durch Ueberführung in Zucker bestimmen, einfacher ist es jedoch, nach den Erfahrungen ron E. Geissler, zur Feststellung des Werthes der Presshefe die reine Hefe selbst zu bestimmen und man verfährt dazu folgendermaassen: Man rührt $3-4 \mathrm{~g}$. Presshefe mit Wasser an, verdünnt und erhitzt bis zur völligen Verkleisterung, giebt dann auf $150 \mathrm{C}$.C. einige Tropfen der officinellen Salzsäure hinzu und erhitzt, bis eine herausgenommene Probe der Flüssigkeit sich mit Jod nicht mehr blau, sondern amaranthroth färbt. Man wäscht dann mehrmals, zunächst durch Absetzenlassen, dann auf gewogenem Filter gut aus, trocknet und wägt die zurückgebliebene ziemlich weisse, vollkommen reine Hefe. (Pharmac. Centralh. 1880. No. 51.)

G. $H$.

\section{Zwei Streupulver mit Carbolsăure und Salieylsăure.} Das Carbolstreupulver, die einfachste Form des antiseptischen Verbandes, wird nach $\mathrm{P}, \mathrm{Bruns}$ in folgender Weise gewonnen: Colophonium 60 und Stearin 15 werden bei gelinder Errärmung geschmolzen und nach theilweisem Erkalten, so lange die Masse noch flüssig ist, Carbolsäure 25 zugesetzt. Diese Mischung wird mit 7-800 Calcaria carbon. präcipit. durch sorgfültiges Verreiben zu einem gleichmässigen Pulver vermischt. Das Pulver wird mittelst einer Streubüchse, welche nach dem Gebrauch fest verschlossen werden kann, auf die Wunde gebracht. Es kann in zweierlei Weise Verwendung finden: 1) Zur unmittelbaren Bestreuung von Wunden und Geschwüren, um eine Heilung unter aseptisehem Schorfe herbeizuführen. 2) Zur extemporirten Herstellung des trockenen Carbol-Juteverbandes. Ueber ein Stück Schutzgaze legt man mehrere Juteschichten, welche nacheinander eingepulvert werden. Es stellt dies Verfahren den billigsten und einfachsten antiseptischen Verband dar.

Vom salicylisirten Stärkemehl sagt Dr. Kersch, dass es kein besseres, zuverlässigeres und so bald zum Ziele fuihrendes Mittel gegen Eczem gebe, als in der von ihm angewandten Form.

Ich lasse, sagt der Verf., bei allen mit Grind, Schorf und Borken einhergehenden Eczemen, jene mittelst einer warmen 2procentigen Carbollösung und Kaliseife ablösen. Ist die Affection von grosser Dimension, geschieht dies in mehreren Sitzungen partionweise, die von Grind befreite Hautpartie wird mit entfetteter desinficirter Watte abgetupft und abgetrocknet, mit einer 2procentigen Lösung von Salicylsäure in möglichst wasserfreiem Alkohol mittelst 